\title{
D-Dimer Levels and Disease Prognosis in COVID-19 Patients
}

\author{
Manisha Khandait ${ }^{1 *}$ (D) , Ishi Sharma² and Rakesh Pandit ${ }^{3}$ (D) \\ ${ }^{1}$ Department of Microbiology, Shree Guru Gobind Singh Tricentenary University, \\ Budhera Gurgaon - 110 075, India. \\ ${ }^{2}$ Department of Pathology, Aakash Pathlab, Aakash Healthcare Super Speciality Hospital, \\ Dwarka, New Delhi, India. \\ ${ }^{3}$ Department of Internal Medicine, Aakash Healthcare Super Speciality Hospital, Dwarka, New Delhi, India.
}

\begin{abstract}
Elevated or abnormal levels of coagulation parameters indicate thrombotic disorders that need to be managed at the earliest to prevent complications and reduce mortality in coronavirus disease (COVID-19) patients. D-dimer is a product that is a part of fibrin abasement, which can be used as a test for the diagnosis of thrombotic disorders. Higher D-dimer levels are a strong indicator of mortality in patients with active COVID-19. This study aimed to determine the relationship between D-dimer levels and the clinical prognosis of COVID-19 patients. This observational, prospective study was conducted between April 2020 and September 2020. All patients with COVID-19 infection were considered for this study, along with their D-dimer values. Patients with higher D-dimer levels and pre-existing morbidities experienced a longer hospital stay and increased complications when compared to patients without pre-existing morbidities. Abnormally elevated D-dimer levels were frequently observed upon admission due to COVID-19 and are analogous to the increased occurrence of critical illness, thrombotic events, acute kidney injury, and death. Therefore, D-dimer levels could be a valuable clinical biomarker and an important indicator of prognosis for patients with COVID-19 with pre-existing morbidities.
\end{abstract}

Keywords: COVID-19, Coronavirus, D-Dimer, Hypercoagulation, Prognosis, Mortality

\footnotetext{
*Correspondence: khandaitm@yahoo.com

(Received: January 13, 2021; accepted: May 07, 2021)

Citation: Khandait M, Sharma I, Pandit R. D-Dimer Levels and Disease Prognosis in COVID-19 Patients. J Pure Appl Microbiol. 2021;15(2):819-825. doi: 10.22207/JPAM.15.2.36

(C) The Author(s) 2021. Open Access. This article is distributed under the terms of the Creative Commons Attribution 4.0 International License which permits unrestricted use, sharing, distribution, and reproduction in any medium, provided you give appropriate credit to the original author(s) and the source, provide a link to the Creative Commons license, and indicate if changes were made.
} 


\section{INTRODUCTION}

The total cases of coronavirus globally, as of October 2020 , are $44,888,869$, and total deaths occurred 1,178,475; whereas total patients who have recovered from COVID-19 infection are 43,710,394. In India, 8,088,851 people have been infected, with 121,090 deaths caused, and the number of recovered patients was $7,667,761^{1}$.

Coronavirus disease (COVID-19) caused by severe acute respiratory syndrome coronavirus 2 (SARS-CoV-2), which emerged in China in December 2019, has spread rapidly across the globe, and has been declared a pandemic ${ }^{2}$. Although there are many general symptoms associated with COVID-19 infection, the most common symptoms include moderate to highgrade fever, dry intermittent cough, soreness and mild pain in the throat, muscular pain and weakness, shortness of breath (SOB), vomiting, and diarrhea ${ }^{3}$. Infection in humans ranges from asymptomatic infection to severe respiratory distress, respiratory arrest, multi-organ failure, and myocardial infarction. Infected asymptomatic human carriers of SARS-CoV- 2 are the main spread of the virus across countries ${ }^{4,5}$. Self-isolation and isolation of symptomatic patients, maintaining social distance between individuals (who may be asymptomatic carriers), along with hand hygiene, wearing masks covering the nose and mouth, maintaining cough etiquette, and undertaking individual responsibilities by following certain norms have been deemed crucial by the World Health Organization (WHO) for eliminating contact transmission of the virus ${ }^{6}$. Most countries, including India, have adopted a nationwide lockdown to educate the public about the disease and to halt community transmission of SARSCoV-2. Many studies have been conducted during the pandemic, and a few studies have reported that the COVID-19 infection is associated with elevated levels of various biological markers, which indicate a poor prognosis among moderate to severely ill patients. An association between death rate and elevated inflammatory markers and coagulation functional indices has been considered, and up on investigation, a relationship has been established between them. The most common mechanism of abnormal coagulation observed in patients hospitalized with COVID-19 is characterized by elevated fibrinogen and D-dimer levels ${ }^{7}$. D-dimer is the main disintegrating product of fibrin and is used as a biomarker of fibrin formation and degradation ${ }^{8}$. D-dimer has been widely estimated and investigated for the diagnosis, monitoring, and treatment of venous thromboembolism , and in conditions of chronic inflammation, such as active malignancy, rheumatoid arthritis, sickle cell disease, and bronchial asthma ${ }^{9,10,11}$. Regarding COVID-19,D-dimer levels have been reported to be elevated in patients who are terminally ill or those who succumb to COVID-19 ${ }^{12,13}$. Additionally, $20.6 \%$ to $30 \%$ of severe COVID-19 patients are observed to develop pulmonary embolism $(\mathrm{PE})^{12,13}$.

\section{MATERIALS AND METHODS}

This prospective, observational study was conducted between April 2020 and September 2020, at Aakash Path lab, Aakash Healthcare Super Specialty Hospital, Dwarka. Demographic variables, such as age, sex, and locality/address, were recorded for the study. We obtained the history of pre-existing morbidities such as diabetes mellitus, hypertension, hyperlipidemia, coronary artery disease (CAD), heart failure, chronic kidney disease, liver disease, and other systemic autoimmune diseases. Patient's taking medications for the above diseases were noted, especially patients who were administered anticoagulants, and data on the duration of the medications was obtained. All samples received were classified as COVID-19 positive (Real TimePolymerase Chain Reaction-RT-PCR) and COVID19samples. Samples for D-dimer were received in a BD Vaccutainer (blue or light blue top with $3.2 \%$ buffered sodium citrate). Samples were collected time to time and sent to the laboratory within 60 minutes of collection. Hemolyzed samples were rejected, and repeat samples were asked. All samples were obtained using a single and bold venepunture. Samples were centrifuged and platelet-poor plasma was obtained using a pipette, and $1 \mathrm{ml}$ of the plasma was transferred to a labeled sample tube and processed in the coagulation analyzer. The inclusion criterion was all (in patients and outpatients)

COVID-19 positive patients with D-dimer values e $1 \mathrm{ng} / \mathrm{mL}$. Samples obtained from catheters, double venepuncture samples and capillary 
collection samples were excluded from this study. If the D-dimer test was performed more than once for a patient, the highest value was considered for this study. The D-dimer assay was performed using the I coagulation analyzer ACL Elite with HemosIL D-Dimer Kits. The positive D-dimer range according to the manufacturer's instructions was 140-3250 $\mathrm{ng} / \mathrm{mL}$. Patients were categorized into normal d $140 \mathrm{ng} / \mathrm{mL}, 140-500 \mathrm{ng} / \mathrm{mL}, 500-1000 \mathrm{ng} / \mathrm{mL}$, $1000-2000 \mathrm{ng} / \mathrm{mL}$, and $>2000 \mathrm{ng} / \mathrm{mL}$.

\section{Statistical Analysis}

Continuous variables are expressed as mean \pm standard deviation and categorical variables are expressed as numbers (percentages).A Chisquared test were performed for the $p$-value. $P$ value of $<0.05$ was considered significant.

\section{RESULTS}

The total number of D-dimer samples included in this study was 1189 of patients with RT-PCR positive for COVID-19. There were 728 (61.22\%) men and 461 (38.78\%) women. The youngest patient in this study was 16 years old and the oldest patient was 69 years old; the mean age was 45.2 years. The redistribution of the cases is shown in Figure 1. The age distribution of the cases is presented in Table 1 . In this study, the highest

Table 1. Age wise distribution of cases

\begin{tabular}{lcc}
\hline Age Group & Number & Percentage \\
\hline 16- 25 years & 116 & 9.76 \\
$26-35$ years & 190 & 15.97 \\
$36-45$ years & 219 & 18.42 \\
$46-55$ years & 318 & 26.75 \\
$56-65$ years & 254 & 21.36 \\
$66-75$ years & 92 & 7.74 \\
Total & 1189 & 100 \\
\hline
\end{tabular}

number of COVID-19 positive cases belonged in the age group $46-55$ years and the lowest was in the age group 66-75 years. D-dimer levels are shown in Table 2. Most patients (397 patients, $33.39 \%$ ) had D-dimer levels of $140-500 \mathrm{ng} / \mathrm{mL}$ and only 24 patients had normal D-dimer levels.

In this study, patients with pre-existing morbidities were taken into consideration and their D-dimer levels were shown in Table 3. Patients that were intaking anticoagulants were also considered, and their D-dimer levels are compared and tabulated in Table 4. We observed that D-dimer levels were higher in patients with COVID-19 infection and pre-existing morbidities than that in COVID-19 patients without preexisting disease. It was also observed that although patients on anti-coagulation therapy for various preexisting conditions showed an almost similar mean \pm SD D-dimer value, the Chi-squared test showed a significant association $(p<0.05)$. This shows that elevated D-dimer levels are partially independent of anticoagulation therapy.

In regard to the duration of hospital stay, we found that patients with higher D-dimer levels required a longer hospital stay (Table 5); some patients developed critical illnesses, acute kidney injury, thrombosis, and even died due to COVID19infection and underlying diseases.

Up on assessing the clinical outcomes of COVID-19 patients, we found that the majority of the patients recovered well from the COVID-19 infection without any complications (698 cases, $58.70 \%$ ), some recovered with minor complications (272 cases, $22.88 \%$ ), few developed critical illnesses and recovered (92 cases, $7.74 \%$ ), while some developed thrombosis ( 56 cases, $4.70 \%$ ), and acute kidney injury (16 cases, $1.34 \%$ );death also occurred in some cases(55 cases, $4.62 \%$ ). Mortality

Table 2. D-dimer levels in the patients

\begin{tabular}{lcc}
\hline D-Dimer levels (Mean \pm SD) & $\begin{array}{c}\text { Number of } \\
\text { patients }\end{array}$ & Percentage \\
\hline$\leq 140 \mathrm{ng} / \mathrm{mL} \quad(87 \pm 16 \mathrm{ng} / \mathrm{mL})$ & 24 & 2.02 \\
$140-500 \mathrm{ng} / \mathrm{mL} \quad(428 \pm 74 \mathrm{ng} / \mathrm{mL})$ & 397 & 33.39 \\
$500-1000 \mathrm{ng} / \mathrm{mL}(863 \pm 162 \mathrm{ng} / \mathrm{mL})$ & 298 & 25.06 \\
$1000-2000 \mathrm{ng} / \mathrm{mL}(1429 \pm 241 \mathrm{ng} / \mathrm{mL})$ & 301 & 25.31 \\
$\geq 2000 \mathrm{ng} / \mathrm{mL}$ & 169 & 14.22 \\
Total & 1189 & 100
\end{tabular}


was observed in cases with high D-dimer levels and respiratory support for more than 10 days (Figure 2). Most of the critical illness and mortality occurred in patients with pre-existing diseases, such as chronic kidney disease, hypertension, diabetes, liver disease, and heart failure. An increased risk of complications was observed in patients with elevated D-dimer levels when compared to the normal D-dimer levels at the time of admission.

\section{DISCUSSION}

Hypercoagulation is a pathological condition that leads to clot formation quicker than normal physiological processes. Acquired hypercoagulation is caused by a disease or other systemic diseases, while inherited coagulation is caused by genetic abnormalities or gene defects. The risk of hypercoagulation is higher in smokers, dehydrated individuals, elderly people, surgery or trauma, human immunodeficiency virus (HIV) infection, cancer, hormone replacement therapy, diabetes mellitus, atrial fibrillation, heart

Table 3. D-dimer levels comparison with pre-existing disease

\begin{tabular}{llll}
\hline Pre-Existing Disease & $\begin{array}{l}\text { Number of Patients } \\
\text { (Percentage } \\
\text { out of 1189) }\end{array}$ & $\begin{array}{l}\text { D-dimer Levels } \\
\text { (Mean } \pm \text { SD) }\end{array}$ & $\begin{array}{l}\text { Higher or Lower compared } \\
\text { to NO pre-existing disease }\end{array}$ \\
\hline Diabetes & $49(4.12)$ & $1396 \pm 260 \mathrm{ng} / \mathrm{mL}$ & $\begin{array}{l}\text { Higher when compared } \\
\text { to NO Pre-Existing }\end{array}$ \\
$\begin{array}{l}\text { Hypertension (HTN) } \\
\text { Hyperlipidemia/ Dyslipidemia }\end{array}$ & $\begin{array}{l}268(22.54) \\
\text { Chronic Renal/Kidney Disease (CKD) }\end{array}$ & $24(2.02)$ & DiseasepValue $<0.05$ \\
Liver disease & $85(7.15)$ & & \\
Heart Failure & $33(2.78)$ & & \\
Coronary Artery disease (CAD) & $28(2.36)$ & $863 \pm 162 \mathrm{ng} / \mathrm{mL}$ & $\begin{array}{l}\text { Lower when compared } \\
\text { Autoimmune Diseases }\end{array}$ \\
NO Pre-Existing Disease & $76(6.40)$ & & Dise-Existing \\
& 473 & &
\end{tabular}

Table 4. D-dimer levels comparison with anti-coagulation therapy

\begin{tabular}{lccc}
\hline & $\begin{array}{c}\text { Number of patients } \\
\text { (Percentage) }\end{array}$ & $\begin{array}{c}\text { D-dimer Levels } \\
\text { (Mean } \pm \mathrm{SD})\end{array}$ & P Value \\
\hline $\begin{array}{l}\text { Anti-Coagulation therapy } \\
\text { for Pre-Existing Disease }\end{array}$ & $515(43.32)$ & $1092 \pm 194 \mathrm{ng} / \mathrm{mL}$ & $<0.05$ (Significant) \\
No Anti-Coagulation therapy & $674(56.68)$ & $863 \pm 162 \mathrm{ng} / \mathrm{mL}$ & $<0.05$ (Significant) \\
\hline
\end{tabular}

Table 5. Hospitalization and D-dimer levels

\begin{tabular}{lcc}
\hline Hospitalization & $\begin{array}{c}\text { Number of Patients } \\
\text { (Percentage) }\end{array}$ & D-Dimer Levels \\
\hline Outpatients & $401(33.72)$ & $<500 \mathrm{ng} / \mathrm{mL}$ \\
$1-5$ DAYS & $265(22.29)$ & 500 to $1000 \mathrm{ng} / \mathrm{mL}$ \\
$6-10$ DAYS & $209(17.58)$ & 1000 to $1500 \mathrm{ng} / \mathrm{mL}$ \\
$11-15$ DAYS & $168(14.13)$ & 1500 to $2000 \mathrm{ng} / \mathrm{mL}$ \\
16-20 DAYS & $146(12.28)$ & $>2000 \mathrm{ng} / \mathrm{mL}$ \\
Total & $1189(100)$ & \\
& & 822 \\
\hline Journal of Pure and Applied Microbiology & www.microbiologyjournal.org
\end{tabular}


disease, and heart failure. Hypercoagulation leads to clot formation at any location in the body and can sometimes belief-threatening. Deep vein thromboses, stroke in the heart or brain, pulmonary embolism, peripheral artery disease, and kidney failure are some of the fatal events that can occur due to hypercoagulation.

The clinical path of patients infected with COVID-19 is highly fluctuating. The risk grouping of comorbidities in COVID-19-positive cases and considering biological markers such as D-dimer, interleukin-6, and serum ferritin levels help in predicting clinical deterioration and the prognosis of patients. Several studies have reported the possible role of D-dimer level as a
COVID-19 biomarkers and an important indicator for prognosis ${ }^{14,15}$.

In this study, the mean age ( 45.2 years) and sex distribution (males, 728 (61.22\%); females, $461(38.78 \%))$ was consistent with the findings of Sharp et al., where males and females comprised $60.78 \%$ and $39.22 \%$ of the study population, respectively ${ }^{16,17}$.

Of the 1189 patients, 1165 patients (97.98\%) had mild to severe elevation of D-dimer levels from the day of hospital admission to the day of discharge. This number is higher when compared to the study conducted by Berger et al., where D-dimer elevation was observed in $86 \%$ of the study population ${ }^{18}$. The increased percentage

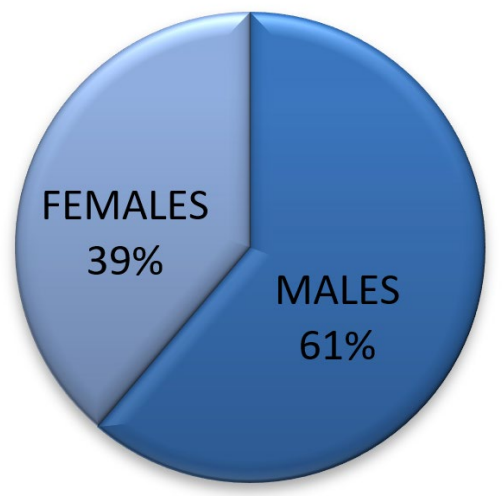

Fig.1. Gender distribution of cases

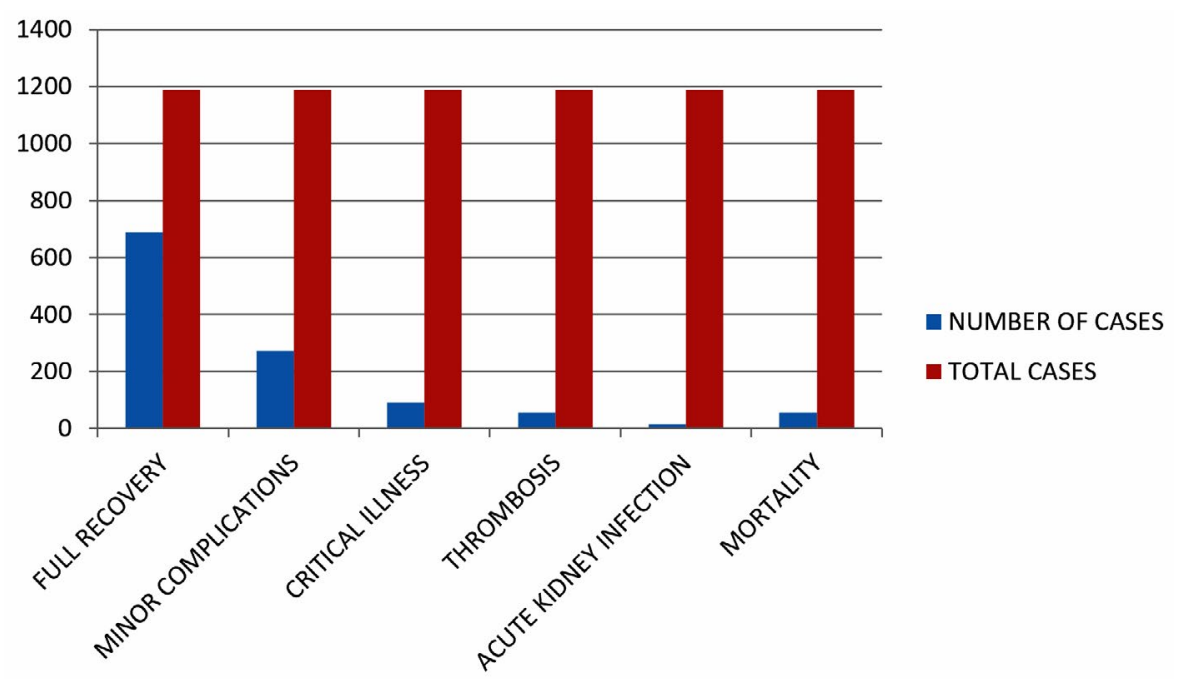

Fig. 2. Chart showing clinical results in patients with abnormal D-dimer 
in this study may be due to late presentation of the patient, late start of treatment, or the severity of symptoms.

In the present study, the elevation of D-dimer level was higher in patients with pre-existing morbidities such as hypertension, diabetes, liver disease, heart failure, and kidney disease. The mean SD D-dimer levels in the COVID-19 positive cases with pre-existing disease were $1396 \pm 260 \mathrm{ng} / \mathrm{mL}$ when compared to the mean SD of $863 \pm 162 \mathrm{ng} / \mathrm{mL}$ in patients without any pre-existing disease. This statement is consistent with the literature stated by Wand et al. and Richardson et al. ${ }^{3,19}$.

Patients with higher D-dimer levels experienced a longer hospital stay when compared to patients with normal or mild elevation of D-dimer. Patients with normal and mildly elevated D-dimer levels were treated on an outpatient basis or hospitalized for less than 5 days and recovered well without complications. This finding is consistent with the findings of Berger et al., Ayanian et al., and Namangan et al. 18,20, 21 .

Up on assessment of the clinical outcomes of COVID-19 patients, it was found that the majority of the patients recovered well from the COVID-19 infection without any complications (698 cases, $58.70 \%$ ), recovered with minor complications (272 cases, $22.88 \%$ ), few developed critical illnesses and recovered (92 cases, $7.74 \%)$, thrombosis was observed in some cases (56 cases, $4.70 \%$ ), along with acute kidney injury (16 cases, $1.34 \%$ ), and mortality (55 cases, $4.62 \%$ ). These findings are also consistent with previous studies done by the authors Berger et al., Ayanian et al., Naymagon et al., Garcia-Olive et al., and Mouhat et al., where in the authors reported that complications, critical illness, thrombosis, and mortality are more common in COVID-19 patients with pre-existing morbidities and high D-dimer levels $18,20,21,22,23$. According to Berger et al., the results of patients with elevated D-dimer levels at the time of admission were very indigent, with $45 \%$ being critically ill, $20 \%$ having thrombosis, and $43 \%$ with acute kidney injury ${ }^{16}$. The soaring thromboembolic risk in COVID-19 patients could be increased by a pro-coagulant state, causing severity of infection, increased inflammatory response, and liver derangement ${ }^{24-28}$.

\section{CONCLUSION}

D-dimer levels and its trends during the course of COVID-19 infection can guide clinicians in recognizing patients who are at a higher risk of poor prognosis. COVID-19 patients with increasing D-dimer levels are associated with a significantly higher risk of complications, critical illness, need for mechanical ventilation, and mortality.

\section{ACKNOWLEDGMENTS}

None.

\section{CONFLICT OF INTEREST}

The authors declare that there is no conflict of interest.

\section{AUTHOR'S CONTRIBUTION}

RP provided Clinical Information. MK and IS prepared the manuscript. IS collects the data statistics and did the editing. MK and RP reviewed and proofread the manuscript.

\section{FUNDING}

None.

\section{DATA AVAILABILITY}

All datasets generated or analyzed during this study are included in the manuscript.

\section{ETHICS STATEMENT}

Not applicable.

\section{REFERENCES}

1. https://www.worldometers.info/coronavirus/

2. WHO, 2020. Rolling Updates on Coronavirus Disease (COVID-19-19). URL https:// www.who.int/ emergencies/diseases/novel-coronavirus-2019/ events-as-they-happen(Accessed on 23-052020).

3. Wang D, Hu B, Hu C, et al. Clinical characteristics of 138 hospitalized patients with 2019 novel coronavirus-infected pneumonia in Wuhan, China. JAMA;2020;323:1061-1069. doi: 10.1001/ jama.2020.1585

4. Lin CY. Social reaction toward the 2019 novel coronavirus (COVID-19-19). Social Health and Behavior. 2020;3(1):1-2. doi: 10.4103/SHB.SHB_11_20 5. Holshue ML, DeBolt C, Lindquist $S$, et al. First case of novel coronavirus, in the United States. The New England Journal of Medicine. 2020;382:929-936. doi: 10.1056/NEJMoa2001191

6. Ahorsu DK, Lin CY, Imani V, Saffari M, Griffiths MD, Pakpour AH. Fear of COVID-19-19 scale: Development and initial validation. International Journal of Mental 
Health and Addiction. 2020. doi: 10.1007/s11469-02000270-8

7. Chen N, Zhou M, Dong X, et al. Epidemiological and clinical characteristics of 99 cases of 2019 novel coronavirus pneumonia in Wuhan, China: a descriptive study. Lancet. 2020;395:507-513. doi: 10.1016/S01406736(20)30211-7

8. AdamSS, Key NS, Greenberg CS. D-dimer antigen:current concepts and future prospects. Blood. 2009;113:28782887. doi: 10.1182/blood-2008-06-165845

9. Bockenstedt P. D-dimer in venous thromboembolism. N Engl J Med. 2003; 349:1203-1204. doi: 10.1056/ NEJMp030084

10. Naik RP, Wilson JG, Ekunwe L, et al. Elevated D-dimer levels in African Americans with sickle cell trait. Blood. 2016; 127:2261-2263. doi: 10.1182/ blood-2016-01-694422

11. Kabrhel C, Mark Courtney D, Camargo CA Jr, et al . Factors associated with positive $\mathrm{D}$-dimer results in patients evaluated for pulmonary embolism. Acad Emerg Med. 2010;17:589-597. doi: 10.1111/j.15532712.2010.00765.x

12. Levi M, Thachil J, Iba T, Levy JH. Coagulation abnormalities and thrombosis in patients with COVID-19. Lancet Haematol. 2020;7:e438-e440. doi: 10.1016/S2352-3026(20)30145-9

13. Shah S, Shah K, Patel SB, et al. Elevated D-Dimer Levels Are Associated With Increased Risk of Mortality in Coronavirus Disease 2019: A Systematic Review and Meta-Analysis. Cardiol Rev. 2020;28(6):295-302. doi: 10.1097/CRD.0000000000000330.

14. Klok FA, Kruip MJHA, Vander-Meer NJM, et al. Confirmation of the high cumulative incidence of thrombotic complications in critically ill ICU patients with COVID-19: An updated analysis. Thromb Res. 2020;191:148-150. doi: 10.1016/j. thromres.2020.04.041

15. Khan IH, Savarimuthu S, Leung MST, Harky A. The need to manage the risk of thromboembolism in COVID-19 patients. J Vasc Surg. 2020;72(3):799-804. doi: 10.1016/j.jvs.2020.05.015

16. Kermali M, Khalsa RK, Pillai K, Ismail Z, Harky A, The role of biomarkers in diagnosis of COVID-19 - A systematic review, Life Sci. 2020; 254: 117788. doi: 10.1016/j.lfs.2020.117788

17. Sharp K, Ghodke B. D-dimer levels in COVID-19 patients and its correlation with age and gender: a retrospective analysis. International Journal of Research and Review.
2020; 7(7): 339-347.

18. JS Berger, D Kunichoff, S Adhikari, et al. Prevalence and Outcomes of D-Dimer Elevation in Hospitalized Patients With COVID-19. Arterioscler Thromb Vasc Biol. 2020;40:2539-2547. doi: 10.1161/ ATVBAHA.120.314872

19. Richardson S, Hirsch JS, Narasimhan N, et al. Presenting characteristics, comorbidities, and outcomes among 5700 patients hospitalized With COVID-19 in the New York City Area. JAMA. 323(20):2052-2059. doi:10.1001/jama.2020.6775

20. Ayanian S, Reyes J, Lynn L, Teufel K. The association between biomarkers and clinical outcomes in novel coronavirus pneumonia in a US cohort. Biomark. Med. 2020;14(12):1091-1097. doi: 10.2217/bmm-20200309

21. Naymagon L, Zubizarreta N, Feld, et al. Admission D-dimer levels, D-dimer trends, and outcomes in COVID-19. Thrombosis Research, 2020;196:99-105. doi: 10.1016/j.thromres.2020.08.032

22. Olive IG, Sintes H, Radua J, Capa JA, Rosell A. D-dimer in patients infected with COVID-19 and suspected pulmonary embolism. Respiratory Medicine, 2020;169: 106023. doi: 10.1016/j.rmed.2020.106023

23. Mouhat B, Besutti M, Bouiller K, et al. Elevated D-dimers and lack of anticoagulation predict $P E$ in severe COVID-19 patients. Eur Respir J. 2020;56(4);2001811. doi: 10.1183/13993003.01811-2020

24. Fan BE, Chong VCL, Chan SSW, et al. Hematologic parameters in patients with COVID-19 infection. Am J Hematol 2020;95(6);E131-E134. doi: 10.1002/ ajh. 25774

25. Tang N, Li D, Wang X, Sun Z. Abnormal coagulation parameters are associated with poor prognosis in patients with novel coronavirus pneumonia. J Thromb Haemost. 2020: 18: 844-847. doi: 10.1111/jth.14768

26. Zhang C, Shi L, Wang FS. Liver injury in COVID-19: management and challenges. Lancet Gastroenterol Hepatol. 2020;5:428-430. doi: 10.1016/S24681253(20)30057-1

27. Guan WJ, Ni ZY, Hu Y, et al. Clinical Characteristics of Coronavirus Disease 2019 in China. N Engl J Med. 2020; 382:1708-1720. doi: 10.1056/NEJMoa2002032

28. Huang C, Wang Y, Li X, et al. Clinical features of patients infected with 2019 novel coronavirus in Wuhan, China. Lancet. 2020;395: 497-506. doi: 10.1016/S01406736(20)30183-5 